\title{
Analysis and Improvement of Material Selection for Process Piping System in Offshore Industry
}

\author{
Karan Sotoodeh* \\ Piping Engineering, Aker Solutions, Oslo, Norway \\ *Corresponding author: karan_sqi@yahoo.com
}

\begin{abstract}
Material failure mainly because of corrosion is a highly dangerous and expensive phenomenon in the offshore sector of the oil and gas industry, associated with severe negative consequences such as loss of asset, loss of production due to plant shutdown, loss of human life, and health, safety, and environment (HSE) problems (e.g. environmental pollution). Additionally, piping systems are produced in large numbers for the topside facilities in the oil and gas plants. Thus, the main aim of this paper is to introduce a novel approach for the piping material selection in the offshore industry to minimize the risk of piping corrosion and weight reduction with an optimum cost. The central focus of the study is to develop a material selection tool based on a systematic material selection approach and the existing literature, standards, and specifications. In this study, the optimal material selection strategy includes three well-known methods of screening: Cambridge material selector, value engineering (VE), and technique for order preference by similarity to ideal solution (TOPSIS). The proposed guideline is a practical reference for material and piping engineers in the offshore industry to select the best choice of material for a specific application. The main finding of this research is that $25 \%$ chromium super duplex stainless steel is the best choice of material for processing piping systems in offshore plants for non-sour process (hydrocarbon) services. Super duplex stainless steel provides a high corrosion resistance and mechanical strength with the advantage of weight reduction for the selected facilities. A method of piping cost analysis is introduced to validate super duplex stainless steel as the most economical option.
\end{abstract}

Keywords: offshore, piping, corrosion, material selection

Cite This Article: Karan Sotoodeh, "Analysis and Improvement of Material Selection for Process Piping System in Offshore Industry.” American Journal of Mechanical Engineering, vol. 6, no. 1 (2018): 17-26. doi: 10.12691/ajme-6-1-3.

\section{Introduction}

Corrosion in the oil and gas industry is a very expensive and harmful phenomenon similar to other natural disasters, such as earthquake, which damage the human health ecosystem, and facilities. Kermani [1] had evaluated the effect of corrosion on three important areas of capital expenses (CAPEX); operation expenses (OPEX); and health, safety, and environment (HSE). In addition, he concluded that $25 \%$ of the failures in the petroleum industry are associated with corrosion failures. As per a research conducted by the National Association of Corrosion Engineers (NACE), in 2001, the cost of corrosion had reached more than US $\$ 600$ billion, which was evaluated as approximately $4 \%-6 \%$ of the gross national product (GNP) of the country. The serious negative impacts of corrosion on the economy and safety have caused engineers and scientists to accept more challenging roles to control and mitigate this phenomenon. Although extensive academic research has been conducted so far on different types of corrosion and its mechanism in the oil and gas industry by engineers, metallurgists, and scientists [2,3,4], no study has specifically addressed material selection for and corrosion of 'piping' in the 'offshore industry.' In fact, selecting materials for piping and valves adds new requirements and parameters in addition to corrosion such as mechanical strength, weight reduction, availability of the material in the market, and cost. Moreover, choosing and designing the materials for offshore industry introduces different requirements regarding the external corrosion risks in a marine environment. Therefore, development of a comprehensive and practical material selection tool, specifically designed for piping in the offshore section of the oil and gas industry is essential.

In addition to the academic papers, there are several international and national codes and standards such as by the American Society of Test and Materials (ASTM), American Society of Mechanical Engineers (ASME), and Norwegian Petroleum Standard (NORSOK), specifying the practical material limitations in different process conditions, which are referred when performing the material selection analysis. However, the issues with the above-mentioned standards are that they do not propose any material for a certain application and they are mostly concerned with material limitations. Thus, the need for a systematic material selection and strategy to identify the best choice of material for a certain application taking into consideration the limits defined in the standards is the main motivation of this research. The key contribution of this study is the development of a material selection flow chart summarizing 
the key findings as a basis for a software development. According to the study conducted on commercial corrosion software, there is no software for selecting a material specifically for piping in the offshore industry. The central aim of this research is to answer the research question: how can a systematic material selection for piping be developed in the offshore industry to the cost of material failure mainly due to corrosion? More specifically, the research has the following main objectives:

1. Development of a model for offshore piping material selection

2. Validation of the proposed material selection concept based on cases in real industry practices;

Material selection as a part of engineering design is the process of choosing the best material for a specific process via a systematic material selection approach. In this study, the optimal material selection strategy includes three well-known methods of screening: Cambridge material selector, value engineering (VE), and technique for order preference by similarity to ideal solution (TOPSIS). Ashbey [5] methods as well as a computer-based system development known as the Cambridge engineering system (CES) are the approaches selected for the preliminary screening. In practice, the design requirements should be translated into a material specification, and then the materials that do not satisfy these requirements should be screened out. VE is a systematic method of ranking the materials based on their performance indices and the weighting properties method (WPM) implemented for quantitative analysis [6]. In fact, the materials are ranked using WPM as a part of VE to achieve an optimized and lowest cost [7]. In addition to the above two methods, TOPSIS, developed by Yoon and Hwang [8], is a method based on multi-criteria decision making (MCDM). The selection made through TOPSIS is the option that is as close as possible to the ideal solution.

\section{Selection Methods}

\subsection{Screening Method}

CES selector software is the core analysis tool for screening. The screening method can be detailed and is summarized as follows:

1. Problem definition and the main function of the component (piping) for which the analysis will be conducted.

2. Model definition identifying the constraints, goals, objectives, and free variables.

3. Defining an object to reduce and screen the candidates to a short list of candidates.

It is important to translate the design conditions and requirements into the specifications of the materials. A chart will be produced based on software such as CES to delete and screen out the materials that cannot satisfy the specification and design requirements. Using the software for initial screening is the starting point of the systematic material selection. Table 1 includes the candidate materials and their limitations based on international codes and standards as well as their corrosion resistance. Table 2 includes the material selection result for each process application after screening process.

Three applications are defined in this research as follows:

1. Process Service (Hydrocarbon), Temperature Range: Between $-46^{\circ} \mathrm{C}$ to $200^{\circ} \mathrm{C}, \mathrm{H}_{2} \mathrm{~S}$ Level: Maximum 1, 5 Psi, CO2 Level: Different Range.

2. Process Service (Hydrocarbon), Temperature Range: Between $-101^{\circ} \mathrm{C}$ to $200^{\circ} \mathrm{C}, \mathrm{H}_{2} \mathrm{~S}$ Level: Maximum 1, 5 Psi, CO2 Level: Different Range.

3. Process Service (Hydrocarbon), Temperature Range: Between $-46^{\circ} \mathrm{C}$ to $200^{\circ} \mathrm{C}, \mathrm{H}_{2} \mathrm{~S}$ Level: more than 1,5 Psi CO2 Level: Different Range.

Table 1. Candidate Materials, Properties and Limitations

\begin{tabular}{|c|c|c|c|}
\hline Material & Hydrocarbon Corrosion Resistance & Limitations & Standards \\
\hline $\begin{array}{c}\text { Carbon and Low-Temperature } \\
\text { Carbon Steel }\end{array}$ & Fair to Good & $\begin{array}{c}\text { Minimum Design Temperature: }-29^{\circ} \mathrm{C} \\
\text { for Carbon Steel and }-46^{\circ} \mathrm{C} \text { for } \\
\text { Low-Temperature Carbon Steel }\end{array}$ & $\begin{array}{c}\text { ASME B31.3 \& NORSOK } \\
\text { M-001 }\end{array}$ \\
\hline Stainless Steel 316 & Good & $\begin{array}{c}\text { Maximum Corrosion Allowance: } 3 \mathrm{~mm} \\
\text { Maximum Operating Temperature } \\
\text { Without coating: } 60^{\circ} \mathrm{C} \\
\end{array}$ & NORSOK L-001 \\
\hline 22Cr Duplex Stainless Steel & Good to Excellent & $\begin{array}{l}\text { Maximum Operating Temperature } \\
\text { Without coating: } 100^{\circ} \mathrm{C} \\
\text { Maximum H2S level: } 1,5 \mathrm{psi} \\
\end{array}$ & $\begin{array}{l}\text { NORSOK M-001 } \\
\text { ISO } 15156\end{array}$ \\
\hline 25Cr Super Duplex-Stainless Steel & Good to Excellent & $\begin{array}{c}\text { Minimum Design Temperature: }-46^{\circ} \mathrm{C} \\
\text { Maximum Operating Temperature } \\
\text { Without Coating: } 110^{\circ} \mathrm{C} \\
\text { Maximum H2S level: } 3 \mathrm{psi} \\
\end{array}$ & $\begin{array}{c}\text { ASME B31.3 \& NORSOK } \\
\text { M-001 } \\
\text { ISO } 15156\end{array}$ \\
\hline $6 \mathrm{MO}$ & Good to Excellent & $\begin{array}{l}\text { Minimum Design Temperature: } \\
46^{\circ} \mathrm{C} \text { Maximum Operating Temperature } \\
\text { Without Coating: } 120^{\circ} \mathrm{C} \\
\text { Maximum } \mathrm{H} 2 \mathrm{~S} \text { level: depends on } \mathrm{H}_{2} \mathrm{~S} \text {, } \\
\text { temperature, and chloride level } \\
\end{array}$ & $\begin{array}{c}\text { ASME B31.3 \& NORSOK } \\
\text { M-001 } \\
\text { ISO } 15156\end{array}$ \\
\hline Nickel Alloy-Inconel 625 & Excellent & $\begin{array}{l}\text { Maximum Operating Temperature } \\
\text { Without Coating: } 120^{\circ} \mathrm{C}\end{array}$ & $\begin{array}{c}\text { ASME B31.3 \& NORSOK } \\
\text { M-001 }\end{array}$ \\
\hline
\end{tabular}

Table 2. Material Screening Result Based on Limitations

\begin{tabular}{|c|l|}
\hline Application No & \multicolumn{1}{c}{ Suitable Candidate Materials } \\
\hline 1 & Carbon and Low-Temperature Carbon Steel, Austenitic Stainless Steel 316, 22Cr Duplex, 25Cr Duplex, 6MO, Inconel 625 \\
\hline 2 & Austenitic Stainless Steel 316, 6MO, Inconel 625 \\
\hline 3 & Austenitic Stainless Steel 316, 6MO, Inconel 625 \\
\hline
\end{tabular}




\subsection{VE Study}

$\mathrm{VE}$ is an innovative and a systematic approach to evaluate and select the best candidate in terms of the value for the spent money. In this study, VE is performed in three different steps as follows:

1. Criteria Definition: In the first step, the list of criteria is created in view of the objectives of the material selection. High hardness and low cost are two examples.

2. Hierarchy Determination: The second step is to evaluate the importance of each criterion (parameter). Each parameter has weight $W_{J}$ that is estimated via a pairwise comparison approach. The total of the weights of the parameters should be 1 as below.

$$
\sum_{i=1}^{j} W_{i}=1 \text {, where } \mathrm{i}=1,2,3, \ldots \mathrm{j} \text {. }
$$

A pair-wise comparison is used to determine the weight values for each parameter defined in the previous section that is shown in Table 3 that is used to determine the weight values and hierarchy of the material properties that are shown in Table 4.

Table 3. Performance Criteria Matrix

\begin{tabular}{|c|c|c|c|c|c|c|c|}
\hline Criteria & $P_{1}$ & $P_{2}$ & $P_{3}$ & $P_{4}$ & $P_{5}$ & Total Score & Normalized \\
\hline$P_{1}$ & $P_{1}$ & 1 & 0 & 1 & 1 & 3 & 0.28 \\
\hline$P_{2}$ & & $P_{2}$ & 0 & 1 & 1 & 2 & 0.18 \\
\hline$P_{3}$ & & & $P_{3}$ & 1 & 1 & 4 & 0.36 \\
\hline$P_{4}$ & & & & $P_{4}$ & 1 & 1 & 0.09 \\
\hline$P_{5}$ & & & & & $P_{5}$ & 1 & 0.09 \\
\hline & & & & & & 11 & 1 \\
\hline
\end{tabular}

$P_{1}$ : Yield Stress (KSI) $P_{4}$ : Ease of Manufacturing

$P_{2}$ : Density $\left(\mathrm{kg} / \mathrm{m}^{3}\right), P_{5}$ : Availability

$P_{3}$ : Corrosion Resistance.

Table 4. Piping Candidate Materials and their Properties

\begin{tabular}{|l|c|c|c|c|}
\hline Material & $\begin{array}{c}\text { Mechanical } \\
\text { Strength } \\
\text { (Yield) KSI }\end{array}$ & $\begin{array}{c}\text { Density } \\
\text { (kg/m3) }\end{array}$ & $\begin{array}{c}\text { Hardnes } \\
\text { (HRC) }\end{array}$ & $\begin{array}{c}\text { Relative } \\
\text { Cost }\end{array}$ \\
\hline $\begin{array}{l}\text { Carbon and Low- } \\
\text { Temperature } \\
\text { Carbon Steel }\end{array}$ & 30 & 7850 & 22 & 1 \\
\hline Stainless Steel 316 & 25 & 8000 & 22 & 3 \\
\hline $\begin{array}{l}\text { 22Cr Duplex } \\
\text { Stainless Steel }\end{array}$ & 65 & 7800 & 28 & 4 \\
\hline $\begin{array}{l}\text { 25Cr Super Duplex- } \\
\text { Stainless Steel }\end{array}$ & 90 & 7800 & 28 & 5 \\
\hline 6MO & 44 & 8000 & 28 & 6 \\
\hline $\begin{array}{l}\text { Nickel Alloy- } \\
\text { Inconel 625 }\end{array}$ & 60 & 8440 & 35 & 10 \\
\hline
\end{tabular}

3. Establishing the baseline: The final step is to assign a score to each material property $\left(C_{\text {Jrate }}\right)$ from 1 to 10 . For this purpose, the following three conditions should be considered:

The first condition is the maximization of the highest value, $V_{M a x}$, in each column in Table 5- Table 10 and converging $V_{\text {Min }}$ to 1 , while scaling the parameters proportionally as per formula 2.

$$
\frac{C_{j \text { Rate }}-1}{10-1}=\frac{V j-V \min }{V m a x-V \min }
$$

Where $V j$ is the $\mathrm{j}^{\text {th }}$ criterion value.

The second condition is that when minimizing a parameter (e.g. cost value), the lowest value is rated 10 , highest value is rated as 1 , and other values are calculated based on formula 3 .

$$
\frac{C_{j \text { Rate }}-10}{1-10}=\frac{V j-V \min }{V \max -V \min } .
$$

The third condition is related to the corrosion values assigned to each material based on the handbook by Perry. The corrosion is rated between 0 and 6 . Each corrosion value should be multiplied by $10 / 6$ to obtain the equivalent score out of 10 .

After establishing the rating for each criterion, a performance function is calculated by multiplying the criterion weight and its rating according to formula 4 .

$$
\text { Performance }=\sum_{i=1}^{j} W_{j} x C_{j \text { Rate }} \text {. }
$$

Considering the fact that the rating is set between 1 and 10 and the weights are between 1 and $100 \%$, the performance value should be between 100 and 1000 .

The average value of performance is chosen as the baseline, and any performance index value higher than the baseline is selected for the next stage of material evaluation. In this research, VE is employed as an intermediate approach between simple screening and TOPSIS to narrow down the material choices.

\subsection{TOPSIS}

TOPSIS is a multi-criteria decision analysis method in which the selected alternative should have the minimum distance geometrically from the positive ideal solution (PIS) and longest geometric distance from the negative ideal solution (NIS). This method starts with building a decision matrix of $\mathrm{X}=x_{i j}$, where the material alternatives represented as $i=1,2, \ldots, n$ are evaluated in connection with the parameters (criteria) represented by $j=$ $1,2,3, \ldots g$. The objective of using TOPSIS is to finalise the material ranking. The criteria are new parameters that were not considered in the VE study. The TOPSIS method is applied according to the following steps:

Step 1) Form a matrix, $\mathrm{X}=x_{i j}$, including $n$ alternatives and $g$ criteria.

Step 2) Generate a normalization matrix by transforming each element of $x_{i j}$ and using the following equation:

$$
r_{i j}=\frac{x_{i j}}{\sqrt{\sum_{i=1}^{n} x_{i j}^{2}}}
$$

Where: $\sqrt{\sum_{i=1}^{n} x_{i j}^{2}}$ is the Euclidean length and $r_{i j}$ is the normalised preference measure for parameter $i$ and criterion $j$.

Step 3) Generate a weighting matrix in which each $r_{i j}$ value is weighted by the relevant weight factors of $W_{j}$ and the formula below,

$$
v_{i j}=W_{j} x r_{i j}
$$


Step 4) Define the positive and negative ideal solutions, which are defined as the most and least preferable candidates, respectively. If we represent the most preferable solution/alternative as $A^{+}$and least preferable solution as $A^{-}$, then these two variables are defined as follows:

$$
\begin{gathered}
A^{+}=\left\{\left(\max _{i}, \min _{i}\right) v_{i j} \mid j \in\left(J, J^{\prime}\right)\right\}=\left\{V_{1}^{+}, \ldots \ldots, V_{g}^{+}\right\} \\
A^{1}=\left\{\left(\min _{i}, \max _{i}\right) v_{i j} \mid j \in\left(J, J^{\prime}\right)\right\}=\left\{V_{1}^{-}, \ldots \ldots, V_{g}^{-}\right\}
\end{gathered}
$$

where,

$$
\begin{gathered}
J=\{1,2, \ldots \ldots g \mid J \text { is related to benefit criteria }\} \\
J^{\prime}=\{1,2, \ldots \ldots g \mid J \text { is related to costcriteria }\} .
\end{gathered}
$$

The reason for the discrimination between the cost and benefit attributes is that the objective for material selection is the minimization of the cost and maximization of the benefit.

Step 5) Measure and calculate the distance between the alternatives and ideal solution, which is called the gEuclidean. The distance from most preferable alternative $A^{+}$and least preferable solution $A^{-}$is calculated from the following formulas:

$$
\begin{aligned}
& \mathbf{S}_{\mathbf{i}}^{+}=\sqrt{\sum_{\mathbf{j}=1}^{\mathbf{g}}\left(\mathbf{v}_{\mathbf{i j}}-\mathbf{v}_{\mathbf{j}}^{+}\right)^{2} \text { for } \mathbf{i}=1,2, \ldots \ldots, \mathbf{n}} \\
& S_{i}^{-}=\sqrt{\sum_{j=1}^{g}\left(v_{i j}-v_{j}^{-}\right)^{2} \text { for } i=1,2, \ldots ., n .}
\end{aligned}
$$

Step 6) This is the final step, and it involves calculating the relative closeness to the ideal solution and finalizing the material ranking. The final ranking is decided by referring to the value of the relative closeness to the ideal solution defined as per formula given below:

$$
C_{i}^{+}=\frac{S_{i}^{-}}{S_{i}^{-}+S_{i}^{+}}
$$

Where

$\mathrm{C}_{\mathrm{i}}^{+}$has a value between 0 and 1 and $\mathrm{i}=1,2, \ldots ., \mathrm{n}$

The best candidate is the one which has the shortest distance to the ideal solution and longest distance to the non-ideal solution. As was mentioned earlier, TOPSIS is an MCDM method based on calculations. The criteria that will be selected for TOPSIS in the final stage are quantitative to complete and finalize the material selection by the VE method.

\section{Offshore Piping Material Selection Case Study}

\subsection{Piping System Definition}

Smith [9] introduced the piping system as a connection of pipes in addition to the fittings, flanges, and valves to transport a fluid between two points (e.g. from one equipment to another). The water supply system in homes, known as plumbing, is an example of a piping system. However, the piping system in this research is a part of an offshore plant to transport hydrocarbons such as oil and gas and utilities such as fresh water, oxygen, seawater, and chemicals.

\subsection{Problem Statement}

The main problem associated with a piping system is corrosion owing to the corrosive offshore environment containing a large amount of chloride and corrosive and untreated internal hydrocarbon (process) fluids. Generally, corrosion resistance alloys (CRAs), such as duplex and nickel alloys, should be selected for an offshore piping system in critical corrosive hydrocarbon fluids to minimize the corrosion. In addition, it is important to select a material with a high mechanical strength and low mass to withstand the loads as well as reduce weight on the platform.

Figure 1 (a) shows the internal corrosion of a pipe caused by hydrogen sulphide $\left(\mathrm{H}_{2} \mathrm{~S}\right)$, and Figure 1 (b) illustrates the external corrosion of a pipeline due to a chloride-containing environment. More specifically, the type of corrosion on the metal in Figure 1(a) is known as hydrogen blistering. This type of corrosion occurs when hydrogen atoms from $\mathrm{H}_{2} \mathrm{~S}$ diffuse to the steel and accumulate in the void spaces inside the material. The accumulation of the hydrogen gas in the cavities or void spaces generates a high pressure from the hydrogen atoms that causes blistering, similar to that shown in the picture, and cracks.

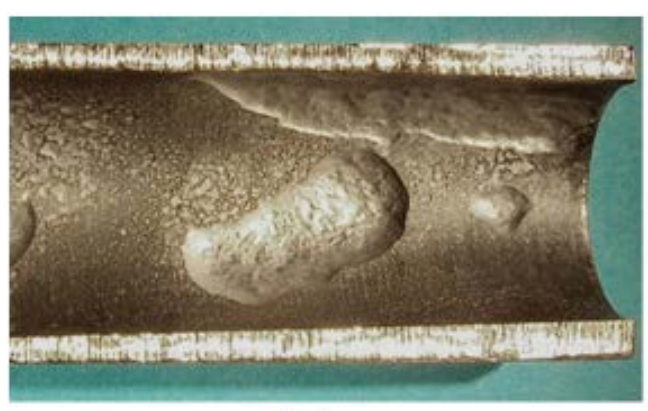

(a)

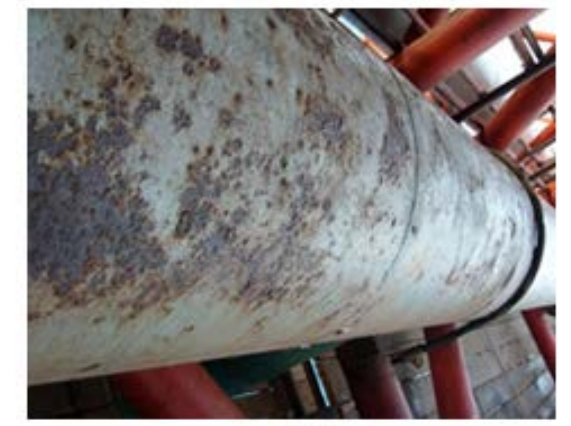

(b)

Figure 1. (a) Internal and (b) External Corrosion of a Pipeline

\subsection{Defining the Applications}

1. Process Service (Hydrocarbon), Temperature Range: Between $-46^{\circ} \mathrm{C}$ to $200^{\circ} \mathrm{C}, \mathrm{H}_{2} \mathrm{~S}$ Level: Maximum 1 , 5 Psi, CO2 Level: Different Range. 
2. Process Service (Hydrocarbon), Temperature Range: Between $-101^{\circ} \mathrm{C}$ to $200^{\circ} \mathrm{C}, \mathrm{H}_{2} \mathrm{~S}$ Level: Maximum 1, 5 Psi, CO2 Level: Different Range.

3. Process Service (Hydrocarbon), Temperature Range: Between $-46^{\circ} \mathrm{C}$ to $200^{\circ} \mathrm{C}, \mathrm{H}_{2} \mathrm{~S}$ Level: more than 1 , 5 Psi CO2 Level: Different Range

\subsection{Preliminary Screening}

In this section, the commonly used materials for piping systems in the offshore industry with their key corrosion resistance are identified for further screening, ranking, and final selection for the different applications listed in the previous section. The corrosion resistance values of the material candidates are useful for process applications based on Perry's handbook [10], and limitations defined in the codes and standards. Table 1 presents the candidate materials with their corrosion resistance properties and limitations based on international and Norwegian codes and standards [11-17].

The objective function is to minimize the corrosion values in the hydrocarbon process services.

Minimising $\mathrm{C}_{i}(\mathrm{i}=1,2,3 \ldots 8)$ (corrosion values in the hydrocarbon process service)

The following ratings have been defined for the general corrosion properties of some metals and alloys [10]:

0: Unsuitable/Not Applicable/Poor

1: Poor to Fair

2: Fair

3: Fair to Good

4: Good

5: Good to Excellent

6: Excellent

The above ranking model streamlines the options for each application

\subsection{Weight Reduction Analysis}

Weight reduction on the platforms is a very important strategy because platforms or jackets as well as lifting cranes have limited load capacities [18]. Two parameters affecting the weight of the piping, namely mechanical strength (yield and allowable stress) and density, are analysed in this section. As per ASME B31.3 (process piping code), the thickness of the pipe is calculated based on formula 15.

$$
t=\frac{P D}{2(P Y+S E)}
$$

Where

$\mathrm{t}=$ Thickness (in), $\mathrm{P}=$ Design Pressure (PSI), $\mathrm{D}=$ Pipe Outside Diameter (in), $\mathrm{Y}=0,4$ (Material Coefficient), $\mathrm{S}=$ Allowable Stress, $\mathrm{E}=$ Joint Efficiency

Allowable stress (S) is a function of the mechanical strength as per the process piping code.

$$
S=F(\text { Mechanical Strength), }
$$

$$
\begin{aligned}
S & =\frac{2}{3} \times \text { Yield Stress } \\
& \text { or } \frac{1}{3} \times \text { Tensile Streess (Whichever is Less) }
\end{aligned}
$$

$$
\begin{gathered}
m=\rho x v \\
v=L \times A \\
A=\frac{\pi}{4}\left(O D^{2}-I D^{2}\right)=\frac{\pi}{4}(O D-I D)(O D+I D) \\
=\frac{\pi}{4}(2 t)(O D+I D)=\frac{\pi}{2} t(O D+I D)
\end{gathered}
$$

Where:

$m=$ Pipe Mass

$\rho=$ Pipe Density

$v=$ Pipe Volume

$L=$ Pipe Length

$A=$ Pipe Cross-Section Area

$O D=$ Pipe Outside Diameter

$I D=$ Pipe Inside Diameter

$t=$ Pipe Thickness.

Formulas 18 and $19 \rightarrow v=L x \frac{\pi}{2} t(O D+I D)$

(Replacing $\mathrm{v}$ in formula 17)

$$
m=\rho \times L \times \frac{\pi}{2} t(O D+I D) .
$$

As per the ASME standards [19], the OD for each size is unique and fixed. The same standards standardize the length of the pipe to either 6 or $12 \mathrm{~m}$. Therefore, the length of the pipe is also a fixed value.

$$
I D=O D-2 x t
$$

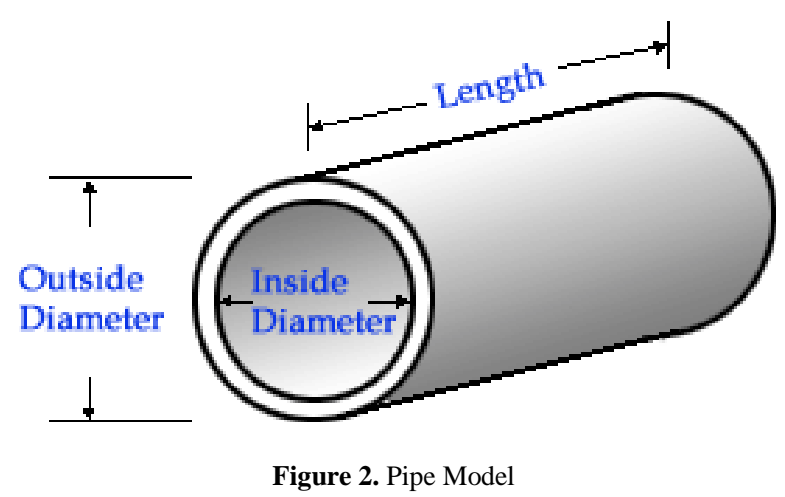

Formulas 20 and $21 \rightarrow$

$$
m=\rho \times L \times \frac{\pi}{2} t(O D+O D-2 \times t)=\rho \times L \times \pi t(O D-t)(22)
$$

Based on formula (21), ID depends on OD and t. In conclusion, the weight (mass) of the pipe depends on the density and thickness as per formula 23.

$$
\mathrm{m}=\mathrm{F}(\rho, \mathrm{t})
$$

As per formula 1 ,

$$
t=F\left(\frac{1}{S}\right)
$$

This implies that increasing the allowable stress (s) and mechanical strength reduces the piping wall thickness. Considering formulas 9 and 10 together, it can be concluded that a lower density and higher mechanical strength reduces the pipe mass

$$
m=F(\rho / s) \text {. }
$$


Therefore, the objective is to reduce the weight of the pipe by reducing the $(\rho / s)$ ratio to the smallest value possible. Material index $\mathrm{M}$ is defined as

$$
M=\left(\frac{S}{\rho}\right) .
$$

Figure 3 illustrates a chart of the material properties (density vs. strength) in a log-log scale.

Considering $\sigma_{f}$ as the material failure strength (function of the allowable stress), formula 27 can be expressed as follows:

$$
\log \left(\sigma_{f}\right)=\log (\rho)+\log (\mathrm{M})
$$

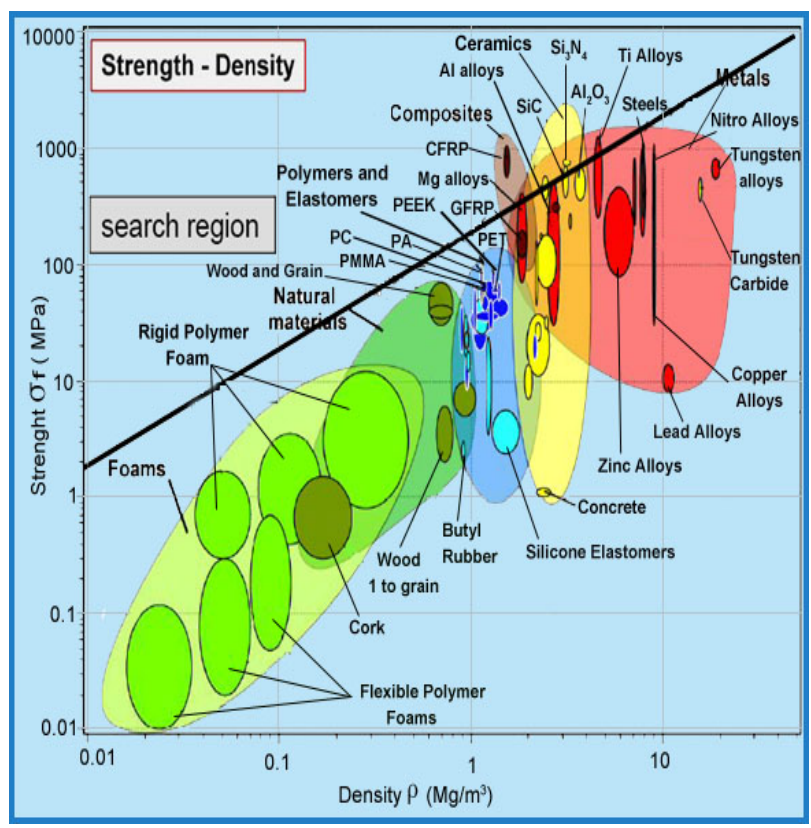

Figure 3. Chart of the Strength and Density of Materials Based on CES Software

\subsection{Value Engineering}

\subsubsection{Criteria Definition}

In the first step, a list of criteria should be created based on the objectives for the material selection. High hardness and low cost are two such examples. In this work, for material selection, the selection criteria are as follows:

a) Mechanical strength (Yield strength): The yield strength is the starting point of an elastic deformation. If the stress level reaches the ultimate stress level which is equal to the tensile strength, the material fails. Herein, the yield stress is less than the tensile stress, and it is used as the measure of strength.

b) Specific weight (Density): The density of the pipe has a direct effect on the mass. Because it is desirable that the pipe mass is minimized to the most extent, a lower density is also an advantage.

c) Corrosion resistance: The materials, as listed in Table 1, should have an acceptable corrosion resistance level in different fluids to withstand the corrosive fluid as well as external corrosive offshore environment during the plant design life.

d) Hardness: The erosion resistance of the material is also an important factor mainly because of the erosive fluid in the pipe containing sand and/or having a high velocity. Harder materials have a better erosion resistance.

e) Cost: The objective is to reduce the CAPEX as much as possible. However, the selection of inexpensive options for materials that cannot satisfy certain listed required parameters, especially when corrosion leads to material failure during the operation, increases OPEX.

\subsubsection{Hierarchy Determination}

A pair-wise comparison known as the performance criteria matrix, presented in Table 3, is used to determine the weight values and hierarchy. Regarding the determination of the weighting values, a value of either 0 or 1 is assigned to the matrix for each compared pair, depending on which one is more important. After comparing all the pairs and assigning scores, the score of each parameter (creation) is calculated. According to Table 3, the corrosion resistance $\left(P_{3}\right)$ is the most important parameter with a score of 0.36 .

\subsubsection{Performance Rating Matrix}

The next step is to create the quantitative and qualitative performance matrices for all the candidate materials based on the property values (e.g. $P_{1}, P_{2}, \ldots$ ) as listed in Table 4 . The material designations are provided in Table 5. Therefore, quantitative and qualitative performance matrixes are provided in Table 6.

Table 5. Material Designation Table

\begin{tabular}{|l|}
\hline C: Carbon Steel and Low-Temperature Carbon Steel \\
\hline A: Austenitic Stainless Steel 316 \\
\hline D: 22Cr Duplex \\
\hline S: 25Cr Super Duplex \\
\hline M: Super Austenitic 6MO \\
\hline N: Nickel Alloy 625 \\
\hline
\end{tabular}

Table 6. Quantitative and Qualitative Performance Matrices

\begin{tabular}{|c|c|c|c|c|c|c|}
\hline Mat. & C & A & D & S & M & N \\
\hline$P_{1}$ & 30 & 25 & 65 & 90 & 44 & 60 \\
\hline$P_{1}$ Rate & 1.7 & 1 & 6.5 & 10 & 3.6 & 5.8 \\
\hline$P_{2}$ & 7850 & 8000 & 7800 & 7800 & 8000 & 8440 \\
\hline$P_{2}$ Rate & 3.2 & 2.9 & 3.3 & 3.3 & 2.9 & 2.0 \\
\hline$P_{3}$ & $\mathrm{FG}$ & $\mathrm{G}$ & $\mathrm{GE}$ & $\mathrm{GE}$ & $\mathrm{GE}$ & $\mathrm{EX}$ \\
\hline$P_{3}$ Rate & 5 & 6.7 & 8.3 & 8.3 & 8.3 & 10 \\
\hline$P_{4}$ & $\mathrm{VE}$ & $\mathrm{E}$ & $\mathrm{E}$ & $\mathrm{E}$ & $\mathrm{E}$ & $\mathrm{E}$ \\
\hline$P_{4}$ Rate & 9 & 7 & 7 & 7 & 7 & 7 \\
\hline$P_{5}$ & $\mathrm{VH}$ & $\mathrm{VH}$ & $\mathrm{VH}$ & $\mathrm{W}$ & $\mathrm{W}$ & $\mathrm{W}$ \\
\hline$P_{5}$ Rate & 9 & 9 & 9 & 7 & 7 & 7 \\
\hline Total Score & 447 & 465 & 685 & 764 & 579 & 686 \\
\hline
\end{tabular}

FG: Fair to Good, G: Good, GE: Good to Excellent, EX: Excellent VE: Very Easy, E: Easy, VH: Very High, W: Widely.

The performance indices for each material are presented in Table 6 for hydrocarbon services. These tables are used to rate each material considering the selection parameters. Each parameter rate assigned from 1 to 10 is calculated based on formulas 15 and 16 . The total score (performance) in the right column is calculated as per formula 17. The values of each parameter for all the candidate materials are listed in Table 4. 
Note 1: The relative cost is based on the prices given by a major Norwegian offshore piping items supplier.

Note 2: Some materials do not have a fixed yield strength and hardness, implying that these two mechanical properties vary with different heat treatments. In these cases, the average of the mechanical properties is provided in Table 4.

Note 3: The quantitative values listed in Table 4 are based on international piping and material standards such as by ASME and ASTM.

Table 6 presents the quantitative and qualitative material performances in hydrocarbon services.

\subsection{TOPSIS}

The last step to finalize the material selection is achieved by using the TOPSIS method. Different material properties such as mechanical strength in the form of yield strength, density, corrosion resistance, ease of manufacturing, and availability were discussed earlier in this study. More material properties including hardness, stiffness, fatigue strength, and cost will be evaluated in this section.

1. Hardness: Hardness of a material is defined as the measure of the resistance of a solid material to different types of shape changes when different loads are applied. Generally, metallic materials are harder than soft materials such as plastics. Hardness of a material depends largely on the inter-molecular bonding and other physical properties such as strength, stress, ductility, and toughness.

2. Stiffness: Stiffness is defined as the minimum deformation of the material under a given load. Simply expressed, stiffness is the rigidity of a material determining the extent to which it can withstand the deformation under the applied load. Therefore, the more flexibility of a material implies less stiffness. The modulus of elasticity, parameter E, represents the stiffness of materials under different types of loads such as tension, compression, and shear.

3. Fatigue Strength: Repeating cyclic stresses with a specific intensity can cause material fracture and brittle cracking. The fracture extension depends on time as well as the frequency and intensity of stress cycles. Fatigue strength is one of the main reasons for material engineering failures.

4. Cost: The cost of material manufacturing and procurement should be kept as low as possible in view of the economic constraints.

The above criteria applied to the present case of TOPSIS are summarized in Table 7.

Table 7. Material Properties and Expected Cost

\begin{tabular}{|c|c|c|c|c|}
\hline Material & $\begin{array}{c}\text { Hardness } \\
(\text { HRC) }\end{array}$ & $\begin{array}{c}\text { Stiffness } \\
\frac{M J}{K g}\end{array}$ & $\begin{array}{c}\text { Fatigue } \\
\text { Strength } \\
(\mathrm{MPa})\end{array}$ & $\begin{array}{c}\text { Relative } \\
\text { Cost }\end{array}$ \\
\hline $\begin{array}{c}\text { Carbon and } \\
\text { Low-Temperature } \\
\text { Carbon Steel }\end{array}$ & 22 & 26 & 290 & 1 \\
\hline Stainless Steel 316 & 22 & 26 & 270 & 3 \\
\hline $\begin{array}{c}\text { 22Cr Duplex Stainless } \\
\text { Steel }\end{array}$ & 28 & 26 & 510 & 4 \\
\hline $\begin{array}{c}\text { 25Cr Super Duplex- } \\
\text { Stainless Steel }\end{array}$ & 28 & 26 & 250 & 6 \\
\hline 6MO & 28 & 26 & 250 & 6 \\
\hline $\begin{array}{c}\text { Nickel Alloy-Inconel } \\
625\end{array}$ & 35 & 24 & 230 & 10 \\
\hline
\end{tabular}

Using Table 7, a decision-making matrix $\mathrm{X}=\left[x_{i j}\right]$ is built, where the materials from $i=1,2, \ldots ., 8$ are evaluated in connection with the criteria $j=1,2, \ldots, 4$.

$$
\mathrm{X}=\left[x_{i j}\right]=\begin{array}{rrrr}
22 & 26 & 290 & 1 \\
22 & 26 & 270 & 3 \\
28 & 26 & 510 & 4 \\
28 & 26 & 550 & 4 \\
28 & 26 & 250 & 6 \\
35 & 24 & 230 & 10
\end{array}
$$$$
\begin{array}{llll}
37 & 16 & 160 & 2 \\
30 & 16 & 160 & 2 . \\
28 & 24 & 630 & 35
\end{array} .
$$

282463035

For each column, Euclidean length $=\sqrt{\sum_{i=1}^{n} x_{i j}{ }^{2}}$ is calculated, and the following values are obtained: 87.17, 71.02, 1132.74, and 37.56.

Next, the weights are obtained for each material property defined in this section using the pair-wise comparison presented in Table 8.

Table 8. Performance Criteria Matrix

\begin{tabular}{|c|c|c|c|c|c|c|}
\hline Criteria & $P_{6}$ & $P_{7}$ & $P_{8}$ & $P_{9}$ & Total Score & Normalized \\
\hline$P_{6}$ & $P_{6}$ & 0 & 0 & 1 & 1 & 0.14 \\
\hline$P_{7}$ & & $P_{7}$ & 1 & 1 & 3 & 0.43 \\
\hline$P_{8}$ & & & $P_{8}$ & 0 & 1 & 0.14 \\
\hline$P_{9}$ & & & & $P_{9}$ & 2 & 0.29 \\
\hline & & & & & 7 & 1 \\
\hline
\end{tabular}

$P_{6}$ : Hardness

$P_{7}$ : Stiffness $\frac{E}{\rho}\left(\frac{M J}{K g}\right)$

$P_{8}$ : Fatigue Strength (Mpa)

$P_{9}$ : Cost.

The next step is to create the normalised decision matrix $\mathrm{R}$ by the below formula.

$$
\begin{aligned}
& r_{i j}=\frac{x_{i j}}{\sqrt{\sum_{i=1}^{n} x_{i j}^{2}}} \\
& 0,25240,36610,25600,0266 \\
& \mathrm{R}=\left[r_{i j}\right]=0,2524 \quad 0,36610,23840,0799 \\
& 0,32120,36610,45020,1065 \\
& 0,32120,36610,48550,1065 \\
& 0,32120,36610,22070,1597 \\
& 0,40150,33790,20300,2662 \\
& 0,4245 \quad 0,2253 \quad 0,14130,0532 \\
& \text { 0,3442 0,2253 0,14130,0532 } \\
& \begin{array}{llll}
0,3212 & 0,3379 & 0,55620,9318
\end{array}
\end{aligned}
$$


The weight values of each criteria for each column based on Table 8 are $0.14,0.43,0.14$, and 0.29 . Using these, the weighted decision matrix (V) is built as

$$
\begin{array}{rrr}
0,0353 & 0,1574 & 0,03580,0077 \\
0, v_{i j}=0,0353 & 0,1574 & 0,03340,0232 \\
0,0450 & 0,1574 & 0,06300,0309 \\
& & \\
0,0450 & 0,1574 & 0,06800,0309 \\
0,0450 & 0,1574 & 0,03090,0463 \\
0,0562 & 0,1453 & 0,02840,0772 \\
& & \\
0,0594 & 0,0969 & 0,01980,0154 \\
0,0482 & 0,0969 & 0,01980,0154 \\
0,0450 & 0,1453 & 0,07990,2702
\end{array}
$$

The ideal and negative ideal solutions are defined as per the matrix given below.

$$
\begin{aligned}
& A^{+}=0,0594 \quad 0,1574 \quad 0,0799 \quad 0,0077 \\
& A^{-}=0,03530,09690,01980,2702
\end{aligned}
$$

The relative closeness and distance to the ideal solution are measured by the formula given below.

$$
\begin{aligned}
& S_{i}^{+}=\sqrt{\sum_{j=1}^{g}\left(v_{i j}-v_{j}^{+}\right)^{2}} \text { for } i=1,2, \ldots \ldots, n \\
& S_{i}^{-}=\sqrt{\sum_{j=1}^{g}\left(v_{i j}-v_{j}^{-}\right)^{2}} \text { for } i=1,2, \ldots \ldots, n \\
& C_{i}^{+}=\frac{S_{i}^{-}}{S_{i}^{-}+S_{i}^{+}} .
\end{aligned}
$$

Therefore, different measures from each material type to the ideal and negative ideal solutions of $\boldsymbol{A}^{+}$and $\boldsymbol{A}^{-}$are calculated in the forms of $S_{i}^{+}$and $S_{i}^{-}$, respectively, as per the above equations.

$$
\begin{array}{cccc} 
& S_{i}^{+} & S_{i}^{-} & C_{i}^{+} \\
C & 0,0484 & 0,2699 & 0,8478 \\
A & 0,0529 & 0,2547 & 0,8280 \\
D & 0,0311 & 0,2508 & 0,8898 \\
S & 0,0290 & 0,2517 & 0,8966 \\
M & 0,0625 & 0,2324 & 0,7881 \\
N & 0,0862 & 0,2003 & 0,6991
\end{array}
$$

The distance to the ideal solution is listed in column $C_{i}^{+}$. The final ranking of the materials is decided based on the decreasing trend of $\mathrm{C}_{i}^{+}$. Therefore, 25Cr duplex and 22Cr duplex are the best choices of materials based on the parameters that have been taken into consideration in the TOPSIS analysis.

\section{Results and Discussion}

\subsection{Introduction}

First, Table 6 presenting the results of the VE study shows super duplex as the best choice of material for hydrocarbon services. The TOPSIS method has proved that super duplex is the best choice of material in terms of the parameters of stiffness, hardness, fatigue strength, and cost. Therefore, it is concluded that super duplex is the best material for all the process services based on both the VE and TOPSIS studies. However, in view of the material limitations defined in Table 1, super duplex cannot be selected for applications 2 and 3 where the minimum design temperature is $-101^{\circ} \mathrm{C}$ (less than the super duplex limit) and $\mathrm{H}_{2} \mathrm{~S}$ is higher than the super duplex resistance in an $\mathrm{H}_{2} \mathrm{~S}$ environment. As per Table 2, austenitic stainless steel 316, 6MO, and Inconel 625 are the three choices of materials for applications 2 and 3. Table 9 compares these three choices for applications 2 and 3 by mixing the results of the TOPSIS and VE methods, assuming that both VE and TOPSIS are equally important with weight factors of $50 \%$.

Table 9. Material Scores for Applications 2 \& 3 based on VE and TOPSIS

\begin{tabular}{|c|c|c|c|}
\hline Material & VE Score (Weight=0.5) & TOPSIS Score (Weight=0.5) & Final Score \\
\hline SS316 & $465(1)$ & $0.8280(10)$ & 5.5 \\
\hline 6MO & $579(5.64)$ & $0.7881(7.2)$ & 6.42 \\
\hline
\end{tabular}

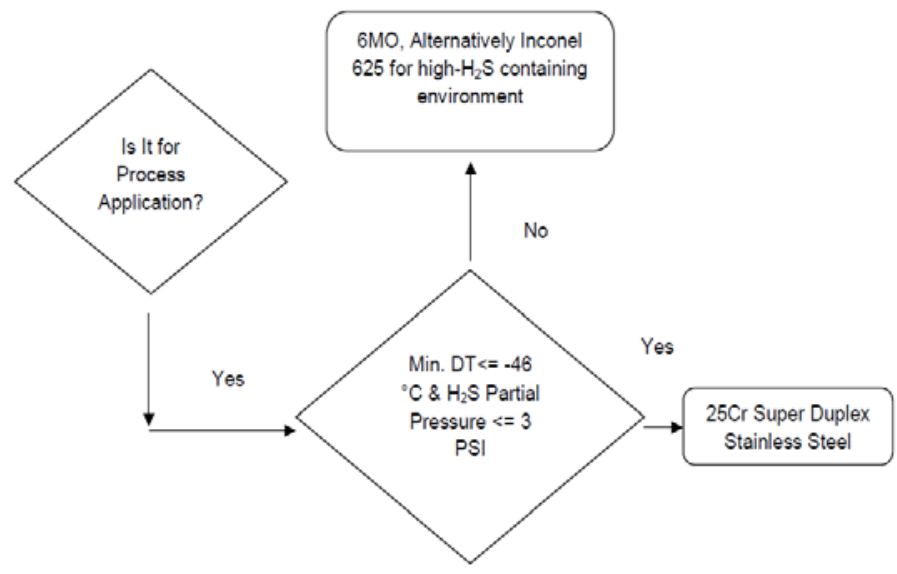

Figure 4. Process Piping Material Selection Flow Chart 
Based on Table 9, 6MO is the best choice of material for applications 2 and 3. However, super duplex is still the best choice of material for application 3 provided the $\mathrm{H}_{2} \mathrm{~S}$ partial pressure is a maximum of 3 PSI in accordance with ISO 15156 standard. 6MO usage in $\mathrm{H}_{2} \mathrm{~S}$ containing services (sour services) has limitations as per ISO 15156; therefore, Inconel 625 is the best choice of material. It is to be noted that super duplex and 6MO should be coated if the operating temperatures are higher than $110^{\circ} \mathrm{C}$ and $120^{\circ} \mathrm{C}$, respectively. Figure 4 illustrates the material selection process in the offshore industry proposed in this paper.

In the Norwegian offshore industry, 22Cr duplex stainless steel is the preferred choice of piping material for process services. The question is how to validate that $25 \mathrm{Cr}$ is a better material for piping compared with carbon steel, SS316, and 22Cr duplex?

The use of 25Cr duplex instead of the other alternatives is validated through the following two steps:

1. Wall thickness and weight calculations of all the three materials to show that super duplex piping has the weight reduction advantage compared with carbon steel and duplex piping.

2. Piping material cost modelling to compare the cost of piping with super duplex and the two alternative materials.

\subsection{Weight Analysis}

Wall thickness calculations were conducted based on ASME B31.3 defined in formula 1 for piping fabricated from the four different materials listed in Table 10. The allowable stress values for carbon steel (ASTM A106 Gr.B), stainless steel 316 (ASTM A312 Gr.316), 22Cr duplex (ASTM A789 UNS S31803), and 25Cr super duplex (ASTM A789 UNS S32750) piping based on Table A1 of ASME B31.3 are 20 KSI; 16,7 KSI; 30 KSI; and 36,3 KSI; respectively. To simplify this task, the wall thickness values are based on NORSOK L-001, Piping and Valves. The calculations were conducted for pipe sizes of 2 to 20 in and pressure classes of $150(\mathrm{PN}=20$ barg), 300 (PN = 50 barg), 600 (PN = 100 barg), 1500 (PN $=250$ barg), and 2500 (PN = 420 barg) listed in Table 10 . Formula 22 was used to calculate the piping weight. ASME B36.10 and B36.19 standards were the references for extracting the values of the piping outside diameter. Figure 5 illustrates the average weight values for a $1-\mathrm{m}$ long pipe for size ranges from 2" to 20" for three material types, namely carbon steel, 22Cr duplex, and 25Cr super duplex, in different ASME pipe classes based on the calculated data presented in Table 10. Carbon steel piping has the highest weight per length according to the chart because carbon steel has the lowest value of mechanical strength when compared with the two other alternatives. In addition, a 3-mm corrosion allowance should be added to the piping thickness as per the NORSOK standard, which increases the thickness and weight of the carbon steel piping. The chart shows that although there is no weight reduction for $22 \mathrm{Cr}$ duplex and $25 \mathrm{Cr}$ super duplex in the low-pressure class of 150, the weight reduction with a super duplex pipe compared with a duplex pipe of the same size in high-pressure classes such as CL2500 is noticeable.
Table 10. Piping Wall Thickness and Weight Values Comparing CS, SS316, DSS, and SDSS Materials in Different Pressure Classes in size ranges from 2 " to 20 ”

\begin{tabular}{|c|c|c|c|c|}
\hline Pressure Class: 150 & \multicolumn{4}{|c|}{ Thickness (mm) } \\
\hline & $\mathrm{CS}$ & SS316 & DSS & SDSS \\
\hline Average Values & 6,95 & 4,06 & 4,06 & 4,06 \\
\hline Pressure Class: 300 & \multicolumn{4}{|c|}{ Thickness (mm) } \\
\hline & CS & SS316 & DSS & SDSS \\
\hline Average Values & 9,56 & 6,98 & 5,35 & 4,71 \\
\hline Pressure Class: 600 & \multicolumn{4}{|c|}{ Thickness (mm) } \\
\hline & CS & SS316 & DSS & SDSS \\
\hline Average Values & 15,61 & 11,93 & 8,98 & 7,25 \\
\hline Pressure Class: 1500 & \multicolumn{4}{|c|}{ Thickness (mm) } \\
\hline & CS & SS316 & DSS & SDSS \\
\hline Average Values & 29,43 & 28,00 & 19,72 & 16,27 \\
\hline Pressure Class: 2500 & \multicolumn{4}{|c|}{ Thickness (mm) } \\
\hline & CS & SS316 & DSS & SDSS \\
\hline Average Values & 44,08 & 42,98 & 29,46 & 26,63 \\
\hline Pressure Class: 150 & \multicolumn{4}{|c|}{ Unit Weight $(\mathrm{kg} / \mathrm{m})$} \\
\hline & CS & SS316 & DSS & SDSS \\
\hline Average Values & 48,95 & 30,29 & 29,53 & 29,53 \\
\hline Pressure Class: 300 & \multicolumn{4}{|c|}{ Unit Weight $(\mathrm{kg} / \mathrm{m})$} \\
\hline & $\mathrm{CS}$ & SS316 & DSS & SDSS \\
\hline Average Values & 72,98 & 56,40 & 42,11 & 36,86 \\
\hline Pressure Class: 600 & \multicolumn{4}{|c|}{ Unit Weight $(\mathrm{kg} / \mathrm{m})$} \\
\hline & CS & SS316 & DSS & SDSS \\
\hline Average Values & 119,21 & 96,82 & 67,74 & 57,04 \\
\hline Pressure Class: 1500 & \multicolumn{4}{|c|}{ Unit Weight $(\mathrm{kg} / \mathrm{m})$} \\
\hline & CS & SS316 & DSS & SDSS \\
\hline Average Values & 214,84 & 215,59 & 150,94 & 126,13 \\
\hline Pressure Class: 2500 & \multicolumn{4}{|c|}{ Unit Weight $(\mathrm{kg} / \mathrm{m})$} \\
\hline & CS & SS316 & DSS & SDSS \\
\hline Average Values & 310,94 & 315,03 & 217,83 & 197,56 \\
\hline
\end{tabular}

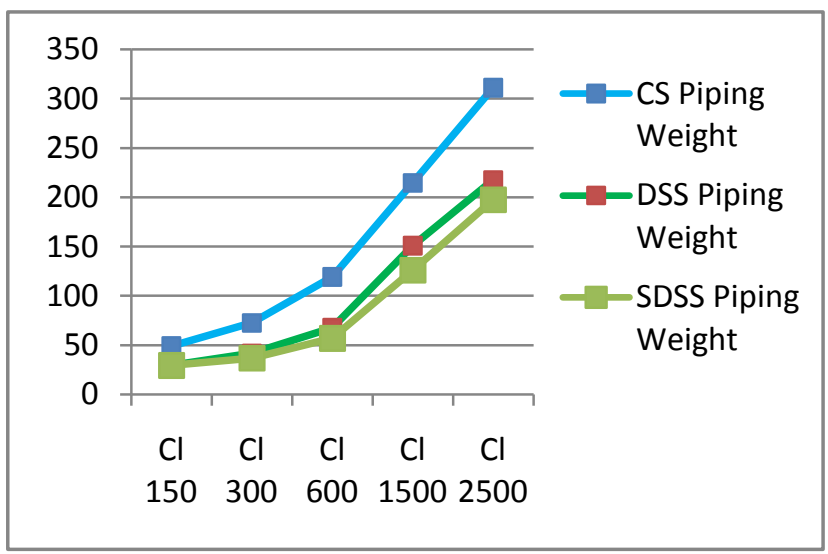

Figure 5. Piping Average Weight Values Comparing CS, DSS, and SDSS Materials in Different Pressure Classes

\subsection{Cost Analysis}

The purpose of this section is to compare the final cost of the materials. The cost analysis presented in the last section for materials in corrosive sea water services is excluded in this section. The main question to be addressed is whether the purchasing cost of materials defines the cost driving factor. The concept is that the selection of CRAs, the so called exotic materials, can be held responsible for drastically increasing the total cost of a project. First, for piping and piping components 
excluding valves, the total cost is estimated as $11 \%$ of the total procurement cost of the materials in a typical offshore project. This implies that an increase in the piping material cost by $50 \%$ would increase the total cost of material by approximately $5 \%$. It is noticeable that the total cost of materials is not just limited to the cost of purchasing. The selection of CRAs such as super duplex has the advantages of weight reduction, less expensive coating, and less pipe support that reduces the final cost of the material compared with an option such as carbon steel.

The following model has been proposed based on Figure 6 for the cost validation [20]:

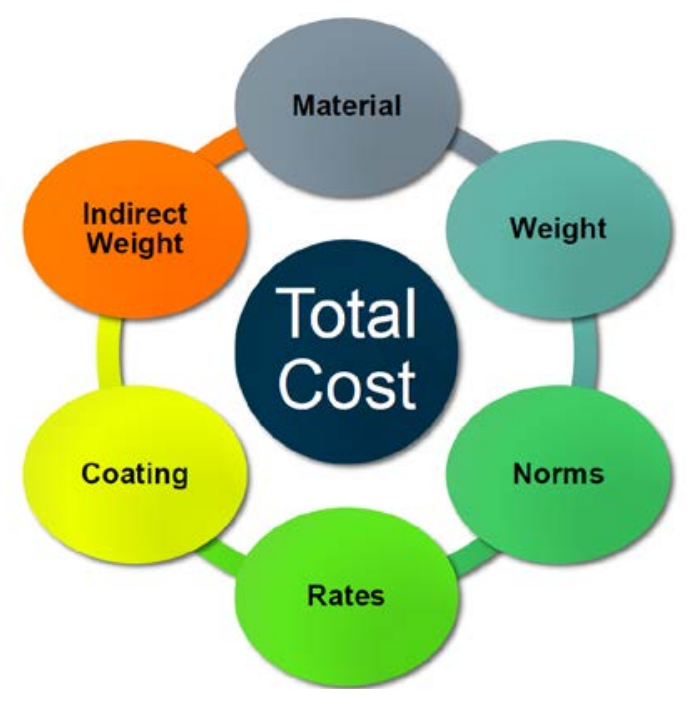

Figure 6. Cost contributors for Piping System

Each factor is explained below:

Material Cost: Cost of the unit weight of piping $(€ / \mathrm{kg})$

Weight: Weight of a $1-\mathrm{m}$ pipe $(\mathrm{kg} / \mathrm{m})$

Norms: Man hours required for fabrication of 1 unit of weight (1 kg of pipe) (mhr/kg)

Rates: Cost per man hour for piping fabrication $(€ / \mathrm{mhr})$

Coating: Cost of coating of a $1-\mathrm{m}$ pipe $(€ / \mathrm{m})$

Indirect Weight: Cost of weight increase that affects adding more structural supports (€/kg)

Accordingly, the total cost of the installed piping is calculated as

$$
\begin{aligned}
\text { Total Cost }= & (\text { material cost } * \text { weight }) \\
& +(\text { norm*rate* weight }) \\
& + \text { coating }+ \text { indirect weight. }
\end{aligned}
$$

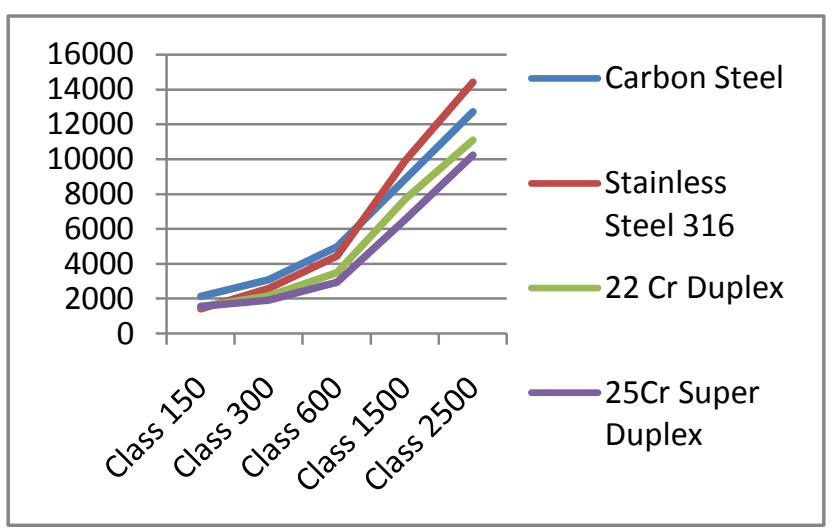

Figure 7. Average Cost of Materials $(€ / m)$ in Different Pressure Classes
The cost analysis was performed for piping composed of four different materials, namely carbon steel, stainless steel 316, 22Cr duplex, and 25Cr duplex, in the different ASME pressure classes. The average cost of materials $(€ / \mathrm{m})$ is illustrated in Figure 7. The plot shows that $25 \mathrm{Cr}$ super duplex is the most economical choice.

\section{Conclusion}

In this study, a robust material selection strategy for process piping systems in the offshore industry was developed by a combination of three material selection methods. On this basis, 25Cr super duplex was identified as the best choice of material for the applications of a high corrosion resistance and high strength which reduce the weight of the piping significantly. Weight and cost analysis were conducted to validate the selected material.

\section{References}

[1] KERMANI M.B., HARROP D. (1996). The impact of corrosion on Oil and Gas Industry. Surrey, UK: SOCIETY OF PETROLEUM ENGINEERS (SPE).

[2] KERMANI M.B., MRSHED A. (2003). Carbon Dioxide Corrosion in Oil and Gas Production- A Compendium. Surrey, UK KEY TECH LIMITED.

[3] ZHENG Y., BROWN B., NESIC S. (2014). Electrochemical Study and Modeling of H2S Corrosion of Mild Steel. Corrosion the Journal of Science and Engineering. Volume 70, No. 4, pp 351-365.

[4] DUGSTAD A., (2006). Fundamental Aspects of CO2 Metal Loss Corrosion Part I. Corrosion NACE Expo2006. Paper No. 06111.

[5] ASHBEY MF., (2005). Materials Selection in Mechanical Design. $3^{\text {rd }}$ edition. Oxford, UK: Butterworth-Heinemann.

[6] FARAG M., (1997). Materials selection for engineering design. Prentice-Hall; p.227-34

[7] STEWART RB., (2005). Fundamentals of value methodology. Philadelphia: Xlibris.

[8] HWANG CL, YOON K., (1981).Multiple attribute decision making: methods and applications. New York: Springer.

[9] SMITH P., (2005). Piping Material Guide. $5^{\text {th }}$ edition, Oxford: ELSEVIER

[10] PERRY R.H. (1999). Perrys Chemical Engineers Handbook. McGraw-Hill

[11] NORSOK M-001, (2014). Material Selection. $5^{\text {th }}$ edition, Lysaker, Norway.

[12] NORSOK L-001, (2017). Piping and Valves. $4^{\text {th }}$ revision, Oslo, Norway.

[13] NORSOK P-001, (2001). Process Systems. $2^{\text {nd }}$ revision, Oslo, Norway.

[14] NORSOK M-506, (2005). $\mathrm{CO}_{2}$ Corrosion Rate Calculation Model. $2^{\text {nd }}$ revision, Oslo, Norway.

[15] AMERICAN SOCIETY OF MECHANICAL ENGINEERS (ASME), (2012). Process Piping. New York, NY.

[16] NATIONAL ASSOSIATION OF CORROSION ENGINEERS (NACE) MR0175-ISO15156, (2015). Petroleum and natural gas industries-Materials for use in H2S containing environments in oil and gas production. Houston, Texas.

[17] AMERICAN SOCIETY OF TEST AND MATERIALS (ASTM) ASTM G48, (2015). Standard Test Methods for Pitting and Crevice Corrosion Resistance of Stainless Steels and Related Alloys by Use of Ferric Chloride Solution. USA.

[18] NUSTAD G., (2015). Tackling Corrosive Challenges in the Oil and Gas Industry. Valve World, 20(11), pp.56-60.

[19] AMERICAN SOCIETY OF MECHANICAL ENGINEERS (ASME), (2004). Carbon, alloy and stainless steel pipes. ASME B36.10/19.

[20] OLE GJERP J. (2015). Material Selection for Offshore Piping Systems-Cost Aspects, Aker Solutions, Norway, Oslo. 